\title{
Peranan Modal Sosial Terhadap Pengembangan Sistem Agroforestri di Kabupaten Bulukumba
}

\author{
Andi Khairil A.Samsu ${ }^{1 *}$,Syamsuddin Millang ${ }^{1}$, Muhammad Dassir $^{1}$ \\ ${ }^{1}$ Fakultas KehutananUniversitas Hasanuddin, Makassar \\ Email: khairiltkd@gmail.com
}

\begin{abstract}
Agroforestry is a concept of sustainability that has various aspects in the implementation and the social capital is one of the important aspect. This study aims to explain how social capital is applicable in community agroforestry management In Kahayya Village, Kindang Sub-district, Bulukumba District. This research uses descriptive qualitative method by using questionnaire method and structured interview with 93 respondents (farmers) who manage the land by agroforestry method. The results indicate that some aspects of social capital, such as social institutions and the level of public confidence shows good value, will be treated in terms of social networking is still showing a bad condition. The level of social capital in agroforestry management in Kahayya Village is at the elementary level of social capital. This can be seen from the condition of the community in the village of Kahayya that still tends to individual welfare but in some cases they are still able to cooperate with other communities if conditions can be mutually beneficial. Such social capital conditions may be used by relevant Institutions and agencies to support sustainable land management through agroforestry patterns as well as institutional strengthening which aims to further increase social capital under adverse criteria.
\end{abstract}

Keywords: Social capital, agroforestry, sustainability, elementary social capital DOI : http://dx.doi.org/10.24259//hm.v11i1.4107

\section{Pendahuluan}

Pengelolaan hutan berbasis masyarakat (PHBM) merupakan salah satu bentuk pengelolaan sumber daya alam secara partisipatif yang menitik beratkan pada aspek ekonomi dalam hal ini peningkatan pendapatan masyarakat, menjaga kelestarian lingkungan dan ketersedian sumberdaya alam serta menciptakan sumberdaya manusia yang berkualitas sebagai pengelola sumberdaya alam, hal ini didasarkan pada UU No.41 Tahun 1999 Pasal 42 ayat 2 yang menjelaskan bahwa penyelenggaraan rehabilitasi hutan dan lahan diutamakan pelaksanaanya melalui pendekatan partisipatif dalam rangka mengembangkan potensi sumberdaya masyarakat. Dalam praktek pengelolaan agroforestri tidak lepas dari konsep pengelolaan hutan berbasis masyarakat. Menurut Putri et al. (2015), partisipasi masyarakat dapat membimbing individu agar memiliki sikap dalam pengelolaan agroforestri yang dapat meningkatkan kesejahteraan. Nawir et al. (2017) menyatakan bahwa agroforestri adalah pola usaha tani produktif yang tidak saja mengetengahkan kaidah konservasi tetapi juga untung dan manfaat yang dapat diperoleh masyarakat.

Salah satu yang menjadi peluang besar untuk mengupayakan kelestarian hutan di Indonesia adalah dengan hadirnya skema-skema pengelolaan hutan berbasis masyarakat, karena kita ketahuai bahwa kelestarian dari suatu hutan tidak lepas dari peran masyarakat yang ada di sekitar hutan.

Agroforestri merupakan konsep keberlanjutan yang memiliki beragam aspek dalam penerapanya, salah satu aspek penting dalam agroforestri ialah aspek modal sosial. Modal sosial merupakan suatu rangkaian proses hubungan antar manusia yang saling berkaitan dan didasari oleh jejaring, norma-norma dan kepercayaan yang memungkinkan kordinasi dan kerjasama demi mencapai keuntungan bersama. Menurut Febriyano et al. (2014), partisipasi masyarakat dalam pengelolaan hutan sangat dipengaruhi oleh keberadaan modal sosial yang ada di masyarakat, dalam penelitianya juga menjelaskan bagaimana tingkat modal sosial masyarakat dalam pengelolaan hutan secara lestari sangat dipengaruhi oleh partisipasi masyarakat dan keberadaan kelembagaan lokal.

Penerapan pola tanam agroforestri hutan lindung sangat terkait dengan kondisi modal sosial yang dimiliki masyarakat. Menurut penelitian yang dilakukan oleh Guilen et all. (2015), modal sosial dalam masyarakat mendukung pengelolaan hutan melalui pola tanam agroforestri yang tentunya menjadi salah satu penentu keberhasilan pengelolaan hutan berbasis masyarakat. 
Kabupaten Bulukumba merupakan salah satu daerah yang dianggap berhasil dalam menerapkan Pengelolaan Hutan Berbasis Masayarakat di Provinsi Sulawesi Selatan sejak di keluarkannya izin pemanfaatan sumber daya hutan tersebut pada November 2011. Sehingga pada tahun 2016 Kabupaten Bulukumba mendapatkan penghargaan dari Kementrian Lingkungan Hidup dan Kehutanan sebagai Kabupaten dengan pengelolaan Hutan Kemasyarakatan $(\mathrm{HKm})$ terbaik Se-Indonesia.

Hadirnya skema HKM di Desa Kahayya, Kecamatan Kindang, Kabupaten Bulukumba merupakan pintu gerbang bagi masyarakat untuk melakukan pengelolaan hutan berbasis sistem agroforestri yang berberlanjutan, namun dalam penerapannya sangat perlu memperhatikan kondisi aspek modal sosial agar tercipta kondisi yang berkesinambungan. Penelitian ini bertujuan untuk menjelaskan bagaimana modal sosial berlaku dalam pengelolaan agroforestri yang dilakukan masyarakat di Desa Kahayya.

\section{Metodologi Penelitian}

\subsection{Tempat dan Waktu}

Penelitian ini dilaksanakan di Desa Kahayya, Kecamatan Kindang, Kabupaten Bulukumba yang merupakan bagian dari Hulu DAS Ujung Loe. Penelitian ini berlangsung pada Bulan September 2017 sampai dengan Bulan Januari 2018.

\subsection{Bahan dan Alat Penelitian}

Alat yang digunakan dalam penelitian ini adalah lembaran kuisioner, alat perekam suara (recorder), perangkat komputer, perangkat lunak berupa program pengelola data statistik (SPSS), perangkat lunak pengolah data tabulasi (Microsoft Excel), Perangkat lunak pengolah data spasial (ArcGis), perlengkapan ATK dan perekam suara.

\subsection{Analisis Data}

Penelitian ini menggunakan metode deskriptif kualitatif dengan menggunakan metode kuisioner dan wawancara terstruktur dengan jumlah responden sebanyak 93 responden (petani) yang mengelola lahan dengan metode agroforestri.

Penelitian ini menggunakan dua jenis data yaitu data primer dan data sekunder, dianalisis menggunakan perangkat lunak pengolah data Microsoft Excel, seanjutnya dianalisis secara deskriptif dengan pendekatan teori modal sosial dari Uphoff (1999), untuk mengkaji unsur-unsur modal sosial berupa :
a.jejaring sosial
b.pranata sosial
c. kepercayaan dan tingkat modal sosial dalam pengelolaan agroforestri.

\section{Hasil Dan Pembahasan}

\subsection{Gambaran Umum Masyarakat di Desa Kahayya}

Desa Kahayya merupakan desa yang terletak di tepi hutan yang berada pada dataran tinggi di kaki Gunung Lompobattang, pada ketinggian antara 1200-1400 mdpl, yang terbagi kedalam 3 dusun diantaranya Dusun Gamaccaya, Dusun Kahayya, dan Dusun Tabbuakkang. Secara administrasi, Desa Kahayya terletak di Kecamatan kindang, Kabupaten Bulukumba, Provinsi Sulawesi Selatan.

Mayoritas masyarakat di Desa kahayya merupakan petani lokal yang telah mengelola hutan secara turun temurun. Desa Kahayya merupakan desa penghasil kopi di Kabupaten Bulukumba. Menurut sejarah, nama Kahayya berasal dari Bahasa Konjo (bahasa lokal) yang berarti kopi. Aspek pendidikan masyarakat Desa Kahayya masih tergolong rendah, hal ini dapat dilihat dari cukup banyaknya masyarakat yang tidak memiliki pengamalan di bangku sekolah. 


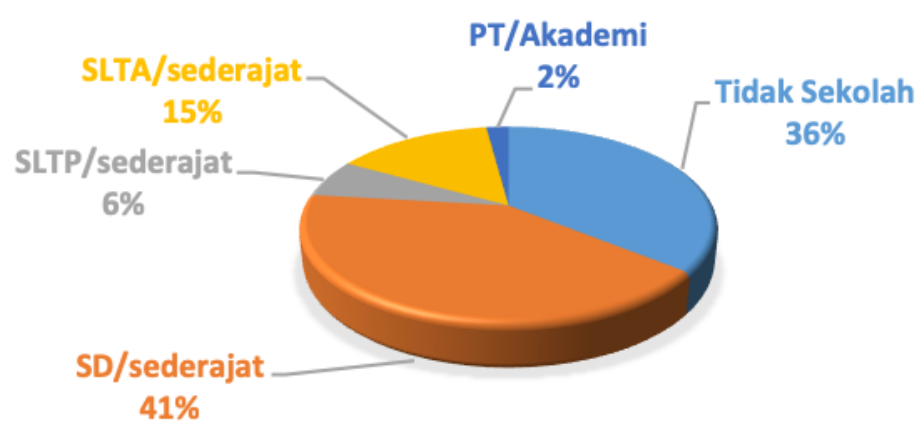

Gambar 1. Tingkat pendidikan di Desa Kahayya

\subsection{Modal Sosial dalam Pengelolaan Agroforestri}

Modal sosial merupakan suatu rangkaian proses hubungan antar manusia yang saling berkaitan dan didasari oleh jejaring, norma-norma dan kepercayaan yang memungkinkan koordinasi dan kerjasama demi mencapai keuntungan bersama (Hasbullah, 2006)

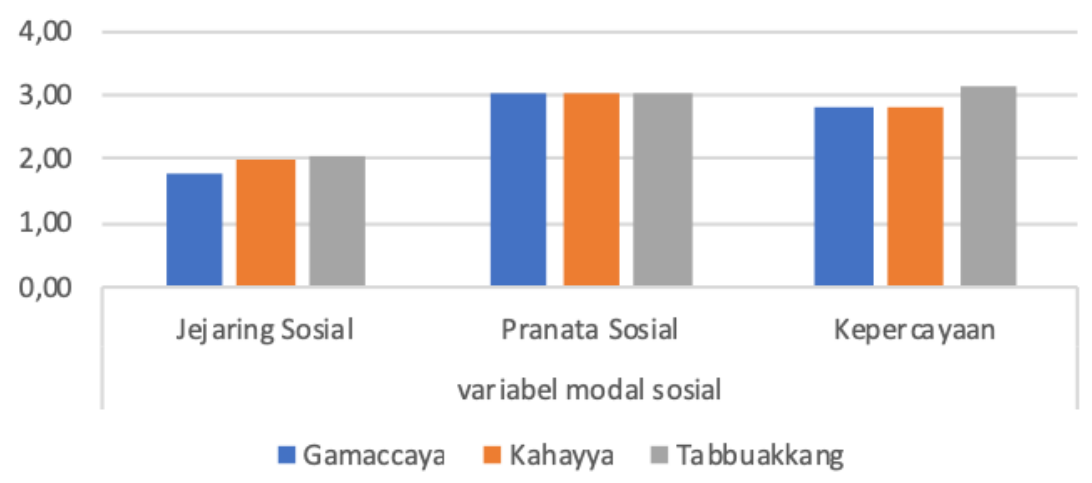

Gambar 2. Kondisi modal sosial dalam pengelolaan agroforestri

\subsection{Jejaring Sosial}

Jejaring Sosial merupakan salah satu aspek penyusun modal sosial. Hasil pengamatan terhadap kondisi jejaring sosial di Desa Kahayya menunjukkan kondisi kurang baik, dapat dilihat dari rendahnya keterlibatan masyarakat dalam kegiatan penyuluhan yang diadakan oleh instansi. Kesadaran petani dalam membangun komunikasi dan mencari informasi dengan pihak luar masih sangat rendah, dapat dilihat dari tingkat mobilitas masyarakat yang cukup rendah. Kebanyakan dari masyarakat Desa Kahayya cenderung tinggal di desa untuk melakukan aktivitas sehari-hari. Hubungan kemitraan petani dalam memasarkan hasil pertaniannya masih sangat sedikit, dapat dilihat dari metode pemasaran hasil bumi yang masih mengandalkan tengkulak dibandingkan memasarkannya secara langsung ke kota. Kondisi status sosial petani sebagian besar tergolong ke dalam kelas menengah kebawah karena sebagian besar masyarakat merupakan petani dengan kepemilikan sarana dan prasarana produksi yang masih tergolong terbatas (petani konvensional), kepemilikan tenaga kerja yang sedikit dan hanya menggunakan tenaga kerja rumah tangga serta pengalaman dan keterlibatan masyarakat dalam kelembagaan yang masih sangat kurang. Variabel jejaring social disajikan pada Tabel 1. 
Tabel 1. Variabel Jejaring Sosial

\begin{tabular}{ccccc}
\hline & \multicolumn{4}{c}{ Variabel Jejaring Sosial } \\
\cline { 2 - 5 } Nama Dusun & $\begin{array}{c}\text { Intensitas } \\
\text { Penyuluhan }\end{array}$ & $\begin{array}{c}\text { Sifat Kesadaran } \\
\text { Petani }\end{array}$ & $\begin{array}{c}\text { Kemitraan } \\
\text { dalam } \\
\text { Pemasaran }\end{array}$ & $\begin{array}{c}\text { Status } \\
\text { Sosial }\end{array}$ \\
\hline Gamaccaya & 1.07 & 1.50 & 2.32 & 2.18 \\
\hline Kahayya & 1.30 & 1.63 & 2.27 & 2.67 \\
\hline Tabbuakkang & 1.16 & 2.00 & 2.51 & 2.54
\end{tabular}

\subsection{Pranata Sosial}

Pranata Sosial merupakan sistem norma yang menata suatu rangkaian tindakan berpola guna memenuhi kebutuhan pokok manusia. Kondisi prana sosial masyarakat di Desa Kahayya dapat dikatakan baik, dikarenakan adanya pemahaman lokal yang masih diterapkan hingga saat ini oleh masyarakat yaitu penggunaan kalender musim dan masih digunakan masyarakat hingga saat ini. Kalender musim bertujuan untuk mengetahui waktu-waktu yang tepat untuk melakukan aktivitas-aktivitas pengelolaan di lahan mereka, waktu yang tepat untuk melakukan penanaman hingga panen serta untuk memprediksi musim hujan dan kemarau. Selain itu terdapat juga kebiasaan baru dalam masyarakat yaitu pesta kopi yang diadakan setahun sekali pasca panen kopi di Desa Kahayya, kebiasaan ini baru berjalan selama 2 tahun namun memiliki arti penting bagi masyarakat utamanya bertujuan untuk mengajak warga dari luar desa agar lebih mengenal tentang kopi khas dari Desa Kahayya.

\subsection{Kepercayaan}

Tingkat kepercayaan merupakan hubungan interaksi dan saling percaya antara elemen-elemen yang terkait dalam pengelolaan agroforestri di Desa Kahayya. Kondisi tingkat kepercayaan masyarakat di Desa Kahayya dalam pengelolaan Agroforestri dapat di katakan cukup baik, hal ini dilihat dari keikut sertaan masyarakat dalam keanggotaan Kelompok tani hutan yang tergolong cukup baik akan tetapi masih, selain itu pemahaman masyarakat terhadap manfaaat agroforestri dari aspek sosial yang cukup tinggi, akan tetapi kepercayaan (Tabel 2) terhadap instansi-instansi terkait masih sangat kurang, hal ini di sebabkan karena kurangnya interaksi masyarakat dengan instansi secara langsung baik secara mandiri maupun dalam bentuk kegiatan.

Tabel 2. Variabel tingkat kepercayaan

\begin{tabular}{|c|c|c|c|c|}
\hline \multirow[b]{2}{*}{ No } & \multirow[b]{2}{*}{ Nama Dusun } & \multicolumn{3}{|c|}{ Variabel Tingkat Kepercayaan } \\
\hline & & $\begin{array}{l}\text { Hubungan } \\
\text { Antar Petani }\end{array}$ & $\begin{array}{c}\text { Kepercayaan } \\
\text { terhadap Pemerintah }\end{array}$ & $\begin{array}{c}\text { Pemahaman terhadap } \\
\text { Aspek Sosial } \\
\text { Agroforestri }\end{array}$ \\
\hline 1 & Gamaccaya & $35,7 \%$ & $7,14 \%$ & $78,57 \%$ \\
\hline 2 & Kahayya & $26,67 \%$ & $20,00 \%$ & $73,33 \%$ \\
\hline 3 & Tabbuakkang & $45,94 \%$ & $13,51 \%$ & $90,54 \%$ \\
\hline
\end{tabular}




\subsection{Tingkat Modal Sosial dalam Pengelolaan Agroforestri}

Tingkat modal sosial dalam pengelolaan agroforestri di Desa Kahayya menunjukkan kondisi cukup baik, dilihat dari beberapa unsur modal sosial seperti pranata sosial dan tingkat kepercayaan masyarakat yang menunjukkan nilai yang cukup baik tetapi dari segi jejaring sosial masih menunjukkan kondisi yang kurang baik.

Berdasarkan teori modal sosial dari Uphoff (1999), tingkat modal sosial dalam pengelolaan agroforestri di Desa Kahayya berada pada tingkat elementary social capital, yang berati masyarakat di Desa Kahayya masih cenderung mementingkan kesejahteraan secara individu tetapi dalam beberapa hal mereka tetap mampu melakukan kerjasama dengan masyarakat lainnya jika kondisinya dapat saling menguntungkan. Hal ini dapat dilihat dari keterlibatan sebagian besar masyarakat dalam pengelolaan secara mengelompok yang bertujuan untuk mencapai hasil yang maksimal. Tingkat elementary social capital dalam pengelolaan agroforestri masih memungkinkan untuk berubah menjadi kondisi yang lebih tinggi

\section{Kesimpulan}

Berdasarkan hasil penelitian yang diperoleh, dapat disimpulkan bahwa modal sosial dalam pengelolaan agroforestri di Desa Kahayya, Kabupaten Bulukumba tergolong cukup baik, didasari dari beberapa unsur modal sosial seperti tingkat kepercayaan dan pranata sosial yang menunjukkan kondisi yang cukup baik meskipun pada jejaring sosial menunjukkan kondisi yang kurang baik. Berdasarkan unsur-unsur tersebut sehingga tingkat modal sosial di Desa Kahayya dapat dikategorikan ke dalam elementary social capital, artinya masyarakat di Desa Kahayya masih cenderung mementingkan kesejahteraan secara individu tetapi dalam beberapa hal mereka tetap mampu melakukan kerjasama dengan masyarakat lainnya jika kondisinya dapat saling menguntungkan. Hal ini dapat dilihat dari keterlibatan sebagian besar masyarakat dalam pengelolaan secara mengelompok yang bertujuan untuk mencapai hasil yang maksimal

\section{Daftar Pustaka}

Coleman, James. (1990). Foundation of Social Theory. Cambridge, Mass.: Harvard University Press, England

Chambers, R., \& Conway, G. R. (1991). Sustainable Rural Livelihoods: Practical Concepts for The 21st Century. IDS Discussion Paper 296.

Ellis, F. (1998). Household Strategies and Rural Livelihood Diversification . The Journal of Develovement Studies, 1-38.

Febriyano, I. G., Suharjito, D., Darusman, D., Kusmana, C., \& Hidayat, A. (2014). The Roles and Sustainability of Local Institution of Mangrove Management in Pahawang Island. Jurnal Manajemen Hutan Tropika, 69-76.

Guillen, L. A., Wallin, I., \& Brukas, V. (2015). Social capital in small-scale forestry : a local case study in Southern Sweden. Procedia Environmental Sciences, 21-28.

Julia, E., \& Amadou, K. (2005). Participatory Landscape/Lifecape Appraisal. Conflict, Social Capital and Managing Natural Resources (pp. 77-88). Oxford: CABI Publishing.

Nawir, M., Taksirawati, I., \& Baharuddin (2017). Pemanfaatan Tanaman Pangi (Pangium Edule Reinw) pada Lahan Agroforestri Desa Watu Toa Kecamatan Marioriwawo Kabupaten Soppeng. Jurnal Hutan dan Masyarakat 9 (2): 123-130.

Putri, R. W., Qurniati, R., \& Hilamnto, R. (2015). Karakteristik petani dalam pengembangan hutan rakyat di Desa Buana Sakti Kecamatan Batanghari Kabupaten Lampung Timur. Jurnal Sylva Lestari, 8998.

Nasir, M. (1983). Metode Penelitian. Jakarta: Ghalia Indonesia. 


\section{斻}

Jurnal Hutan dan Masyarakat. Vol. 11(1): 73-78, Juli 2019

Diserahkan : 2018-05-06; Diterima: 2019-07-31

ISSN: 1907-5316 ISSN ONLINE: 2613-9979

Putnam, R. (1995). The Prosperous Community - Social Capital and Public Life". American Prospect. Washington DC: World Bank

Prayitno, H., \& Arsyad, L. (1987). Petani desa dan kemiskinan. Yogyakarta: BPFE.

Rauf, A. (2004). Agroforestri dan Mitigasi Perubahan Lingkungan. Makalah Falsafah Sains Sekolah Pasca Sarjana IPB

Uphoff, N. (2000). Understanding Social Capital : Learning From The Analysis And Experience Of Participation In Dasgupta And Serageldin (eds). 2000 Social Capital : A Multifaceted Perspective. Washington DC: The Word Bank. 